\title{
Expression of Pentraxin 3 and Thrombospondin 1 in Gingival Crevicular Fluid during Wound Healing after Gingivectomy in Postorthodontic Patients
}

\author{
Anne Marie Rauten, ${ }^{1}$ Isabela Silosi, ${ }^{2}$ Stefan Ioan Stratul, ${ }^{3}$ Liliana Foia, ${ }^{4}$ Adrian Camen, ${ }^{5}$ \\ Vasilica Toma, ${ }^{6}$ Daniel Cioloca, ${ }^{6}$ Valeriu Surlin, ${ }^{7}$ Petra Surlin, ${ }^{8}$ and Maria Bogdan ${ }^{9}$ \\ ${ }^{1}$ Department of Orthodontics, University of Medicine and Pharmacy, Strada Petru Rares 2, 200349 Craiova, Romania \\ ${ }^{2}$ Department of Immunology, University of Medicine and Pharmacy, Strada Petru Rares 2, 200349 Craiova, Romania \\ ${ }^{3}$ Department of Periodontology, Victor Babes University of Medicine and Pharmacy, P-ta Eftimie Murgu 2A, \\ 300041 Timisoara, Romania \\ ${ }^{4}$ Department of Biochemistry, Grigore T. Popa University of Medicine and Pharmacy, Strada Universitatii 16, 700115 Iasi, Romania \\ ${ }^{5}$ Department of Oral Surgery, University of Medicine and Pharmacy, Strada Petru Rares 2, 200349 Craiova, Romania \\ ${ }^{6}$ Department of Surgery, Grigore T. Popa University of Medicine and Pharmacy, Strada Universitatii 16, 700115 Iasi, Romania \\ ${ }^{7}$ Department of Surgery, University of Medicine and Pharmacy, Strada Petru Rares 2, 200349 Craiova, Romania \\ ${ }^{8}$ Department of Periodontology, University of Medicine and Pharmacy, Strada Petru Rares 2, 200349 Craiova, Romania \\ ${ }^{9}$ Department of Pharmacology, University of Medicine and Pharmacy, Strada Petru Rares 2, 200349 Craiova, Romania
}

Correspondence should be addressed to Petra Surlin; psurlin@hotmail.com

Received 16 December 2015; Revised 17 April 2016; Accepted 10 May 2016

Academic Editor: Douglas C. Hooper

\begin{abstract}
Copyright (C) 2016 Anne Marie Rauten et al. This is an open access article distributed under the Creative Commons Attribution License, which permits unrestricted use, distribution, and reproduction in any medium, provided the original work is properly cited.

Background. Wound healing is a tissue repair process after an injury, and two of its main components are inflammation and angiogenesis, in which course a cascade of mediators is involved. The aim of this research was to evaluate the involvement of Pentraxin 3 and Thrombospondin 1 in wound healing after periodontal surgery (gingivectomy) for gingival overgrowth during orthodontic treatment with or without magnification devices, by assessing their levels in GCF. Methods. From 19 patients with gingival overgrowth as a result of fixed orthodontic treatment, the overgrown gingiva was removed by gingivectomy, from one half of the mandibular arch without magnification and from the other under magnification. Pentraxin 3 and Thrombospondin 1 were determined from gingival crevicular fluid by ELISA tests. Results. Statistically significant differences $(p<0.05)$ and correlations between levels of the two biomarkers were analyzed. Statistically significant differences were established between levels of the two biomarkers at different time points, with significant positive correlation at the point of 24 hours. Conclusions. Within the limitations of this study, the results seem to sustain the involvement of Pentraxin 3 and Thrombospondin 1 in the processes of inflammation and angiogenesis in wound healing of patients with postorthodontic gingivectomy. The dynamics of Pentraxin 3 and Thrombospondin 1 levels could suggest a reduced inflammation and a faster angiogenesis using microsurgery.
\end{abstract}

\section{Introduction}

As an exudate that reflects with fidelity the events in the periodontium, the gingival crevicular fluid (GCF) may be used to determine the levels of certain biomarkers [1]. Expressions of biologically active substances in GCF in periodontal disease and its nonsurgical treatment [2-4], during initial phase of orthodontic tooth movement [5-7], or after various periodontal surgical techniques [8] were highlighted so far.

Today, gingivectomy remains the oldest and one of the basic periodontal surgical procedures [9], without vertical incisions and sutures which are considered to determine local inflammation $[10,11]$. The development of more sophisticated flap methods have relegated the gingivectomy to a lesser role 
in the current repertoire of available techniques; between its limited indications remained the resection of gingival enlargement, including gingival overgrowth (GO) as a result of orthodontic treatment. Most of the time, the removal of $\mathrm{GO}$ is performed at the end of the orthodontic treatment, when GO does not regress spontaneously [12].

Although periodontal microsurgery presumes previous training of the operator, skills, expensive magnification devices, specific surgical instruments, and longer operative time, it is often used in practice due to its clinical advantages determined by the good postoperative clinical course: a faster healing of the gingival mucosa, reduced signs of local inflammation, and less pain for the patient [13]. These clinical advantages of periodontal microsurgery were studied during the coverage of gingival recessions [14] and the regenerative surgical treatment of infraosseous defects [15].

Similar results were found for other tissues, in which healing was faster after microsurgery [16]. There are studies trying to bring scientific proofs for the clinical observations by determining the levels of matrix metalloproteinase 2 (MMP2), matrix metalloproteinase 9 (MMP9), TGF-1beta, and TNF alpha $[17,18]$ to emphasize the role of microsurgical approach in reducing the inflammation and stimulating the angiogenesis involved in the healing process.

Wound healing is a tissue repair process after an injury, and two of its main components are inflammation and angiogenesis, in which course a cascade of mediators is involved [19].

Pentraxin 3 (PTX3) is an acute phase protein that belongs to the pentraxin superfamily (with $\mathrm{C}$ reactive protein, CRP, and serum protein A, SAP) and is considered to be a marker of inflammation $[20,21]$. PTX3 is a long pentraxin produced especially by fibroblasts and neutrophils $[22,23]$. The levels of PTX3 in GCF in periodontal health and disease or during orthodontic treatment were estimated in previous studies [24, 25]. On the other hand, there are findings that link the PTX3 expression to fibroblast growth factor 2 (FGF2) suggesting the involvement of PTX3 in angiogenesis downregulating [26, 27].

Thrombospondin 1 (TSP1) is a glycoprotein and is one of the endogenous inhibitors of angiogenesis, of which main antiangiogenic site is type I collagen repeats, active both as whole molecule and as fragments [28]. Implication of TSP1 in inhibiting the angiogenesis is by direct mechanism through interaction with specific receptors and indirect by influencing the activity of other mediators of angiogenesis [29].

The aim of this research was to (1) evaluate the involvement of PTX3 and TSP1 in wound healing after gingivectomy with or without microsurgical instruments and magnification devices, by assessing their levels in GCF and (2) evaluate if the more favorable clinical course of wound healing in case of microsurgery reported by other previous studies could be explained through the different dynamics of PTX3 and TSP1 levels.

\section{Materials and Methods}

2.1. Subjects. 19 patients aged between 14 and 32 years (mean age $18.42 \pm 5.46$ ) were included (11 women and 8 men). All patients presented with gingival overgrowth with maximum score of 2 [30] as a result of fixed orthodontic treatment of the mandibular arch, after 1 month of contention. The ethical approval was given by the Committee of Ethics, Academic and Scientific Deontology of University of Medicine and Pharmacy, Craiova, Romania, and patients gave informed consent. Inclusion criteria were as follows: (1) gingival overgrowth including at least 6 teeth in the mandibular anterior zone; (2) no attachment loss; (3) no radiographic sign of bone loss. Exclusion criteria were as follows: (1) systemic diseases and treatments leading to gingival hypertrophy; (2) antiinflammatory treatments during the last 30 days; (3) antibiotic treatment in the last 3 months; (4) pregnancy. All patients were nonsmokers. One week before surgery, all patients underwent a session of ultrasonic scaling and received indications regarding the oral hygiene to obtain a good control of the bacterial plaque: dental brushing twice a day with the same toothpaste available on the market (Colgate Total, USA) and mouth rinsing with chlorhexidine $\mathrm{CHX} 0.12 \%$ twice a day, 30 min after teeth brushing.

2.2. Surgery. The overgrown gingiva was removed from one half of the mandibular arch by gingivectomy [9], without microsurgical instruments and without magnification, and from the other half by the same surgical technique performed under magnification by using a dental microscope (Seliga, Seliga Microscopes Sp. z.o.o., Lodz, Poland), microsurgical blades, and microsurgical instruments (Hu Friedy, Chicago, IL, USA, by RED Intl). Prior to the surgery, the depths of the false pockets were identified by probing with a periodontal probe (UNC15, Hu Friedy, Chicago, IL, USA, by RED Intl). External bevel scalloped incisions one millimetre coronally from the base of the false pockets were performed. Haemostasis was achieved by gentle gauze packing. Surgeries were performed in the morning, between 10.00 and 11.00 a.m., 2 hours after domestic hygiene and 1 hour after first sampling of GCF. After the procedure, patients were recommended to maintain hydration in the first $24 \mathrm{~h}$ with nonacidulated sugar-free beverages and to stay on a liquid diet. The same indications for oral hygiene were maintained for the next 2 weeks, except the 2 nd brushing on the day of surgery.

2.3. GCF Sampling. Samples of GCF were obtained (one sample/site/tooth) using paper strips (PerioPaper, Oraflow Inc., Smithtown, NY, USA), maintained for $30 \mathrm{sec}$ in the gingival sulcus, at 1 minute interval [31], from a mandibular tooth with gingivectomy performed with microsurgical instruments under magnification, test tooth $\mathrm{M}$ (TTM), and without microsurgical instruments and no magnification, test tooth $\mathrm{G}$ (TTG), and from a maxillary tooth without hypertrophy and no gingivectomy, control tooth (CT). Prior to the procedure, the supragingival plaque was gently removed with a Gracey curette (HU Friedy, IL, USA) and the area was isolated with cotton rolls while using a saliva ejector. Samplings were done 1 hour before gingivectomy (considered as baseline level of the two markers) and at 24, 72, and 120 hours and 1 and 2 weeks after gingivectomy, in the morning, and 1 hour after the first mouth hygiene of the day. The method of GCF collection and the calculation of the concentration were performed 
as previously described [32]. In short, the harvested GCF volume was measured with a precalibrated device (Periotron 8000 , Oraflow Inc., Smithtown, NY, USA) designed to measure volumes of $10^{-6} \mathrm{~L}(\mu \mathrm{L})$ and samples were introduced in polypropylene tubes with $100 \mu \mathrm{L}$ PBS and stored at $-20^{\circ} \mathrm{C}$ prior to their use. In the case of saliva or blood contamination, the sample was discarded and repeated in another site with gingivectomy. Calculation of the concentration in each sample was performed by dividing the amount of substances by the volume of the sample $(\mathrm{ng} / \mathrm{mL})$.

2.4. Immunological Assays in GCF. For quantitative determination in GCF, commercial kits Quantikine Elisa Kit (R\&D Systems, USA) for PTX3 (test sensitivity $0.116 \mathrm{ng} / \mathrm{mL}$ ) and TSP1 (test sensitivity $0.944 \mathrm{ng} / \mathrm{mL}$ ) were used. Every component of the kit was used according to the manufacturer's indications. Reading was performed at $450 \mathrm{~nm}$ with a correction at $540 \mathrm{~nm}$ to reduce optical imperfections on the reading plate.

2.5. Statistical Analysis. Statistical analysis was performed with a dedicated software (SPSS 16.0, Chicago, IL, USA). The mean \pm standard deviation $(\mathrm{M} \pm \mathrm{SD})$ was used as primary data. The results were statistically analyzed using the nonparametric Mann-Whitney $U$ test $(p<0.05$ for statistical significance). Bonferroni correction was applied. Pearson correlation coefficient was used to verify if there was correlation between levels of PTX3 and TSP1.

\section{Results}

The results obtained for the TTG showed an increase of GCF levels of PTX3 from $1.05 \mathrm{ng} / \mathrm{mL} 1$ hour before gingivectomy $(-1 \mathrm{~h}$ as baseline level) to a maximum of $5.43 \mathrm{ng} / \mathrm{mL}$ (approximately 5-fold compared to the baseline level) at 24 hours, followed by a decrease reaching $1.08 \mathrm{ng} / \mathrm{mL}$ at 2 weeks (Figure 1).

In the TTM group, the results showed an increase of PTX3 values from $1.12 \mathrm{ng} / \mathrm{mL}$ at $1 \mathrm{~h}$ before gingivectomy $(-1 \mathrm{~h}$ at baseline level) to a maximum of $4.42 \mathrm{ng} / \mathrm{mL}$ (approximately 4 -fold compared to the baseline level) at 24 hours, followed by a decrease reaching the baseline value $1.05 \mathrm{ng} / \mathrm{mL}$ at 120 hours, and were maintained at this level after 1 and 2 weeks (Figure 1).

For the TSP1 levels in TTG, an increase of values from $18.91 \mathrm{ng} / \mathrm{mL} 1$ hour before gingivectomy $(-1 \mathrm{~h}$ as baseline level) to a maximum of $37.84 \mathrm{ng} / \mathrm{mL}$ (approximately 2 -fold compared to the baseline level) at 72 hours and a decrease to $18.91 \mathrm{ng} / \mathrm{mL}$ at 2 weeks (Figure 1) were noted.

For the TSP1 levels in TTM, an increase from $18.93 \mathrm{ng} / \mathrm{mL}$ 1 hour before gingivectomy $(-1 \mathrm{~h}$ as baseline level) to a maximum of $34 \mathrm{ng} / \mathrm{mL}$ (approximately 1.7-fold compared to the baseline level) at 72 hours and a decrease to $18.61 \mathrm{ng} / \mathrm{mL}$ at 2 weeks (Figure 1) were noted.

Statistically significant differences $(p<0.05)$ were found between mean levels of PTX3 in TTG at 24, 72, and 120 hours and the baseline level. There was no statistically significant difference $(p>0.05)$ between the levels at 1 week and 2 weeks and the baseline level. Statistically significant differences

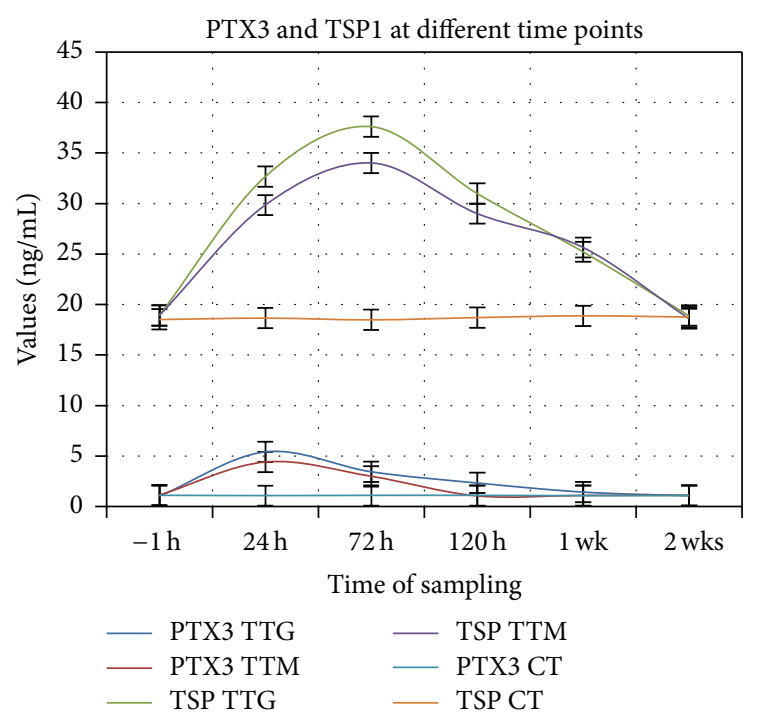

FIgure 1: Dynamics in time of PTX3 and TSP1 levels in TTG and TTM. Levels in $\mathrm{ng} / \mathrm{mL}, \mathrm{M} \pm \mathrm{SD}$. Maximum levels for PTX3 at $24 \mathrm{~h}$ and for TSP1 at $72 \mathrm{~h}$ in both TTM and TTG.

$(p<0.05)$ were found between mean levels of PTX3 in TTM at 24 and 72 hours and the baseline level. There were no statistically significant differences $(p>0.05)$ between the levels at 120 hours, 1 week, and 2 weeks and the baseline level. Levels of PTX3 in TTG were higher as in TTM at 24, 72, and 120 hours and 1 week, statistically significant differences $(p<0.05)$ being found between mean levels of PTX3 in TTG and TTM at 24 (maximum levels for both TTG and TTM) and 120 hours (levels in TTM reaching the baseline level). There was no statistically significant difference $(p>0.05)$ between the levels of PTX3 in TTG and TTM at baseline $(-1 \mathrm{~h}), 72$ hours, 1 week, and 2 weeks (Figure 2(a)).

Statistically significant differences $(p<0.05)$ were found between mean levels of TSP1 in TTG at 24, 72, and 120 hours and 1 week and the baseline level. There was no statistically significant difference $(p>0.05)$ between the levels at 2 weeks and the baseline level. Statistically significant differences $(p<$ 0.05 ) were found between mean levels of TSP1 in TTM at 24, 72 , and 120 hours and 1 week and the baseline level. There was no statistically significant difference $(p>0.05)$ between the levels at 2 weeks and the baseline level. Levels of TSP1 in TTG were higher as in TTM at 24, 72, and 120 hours, statistically significant differences $(p<0.05)$ being found between mean levels of TSP1 in TTG and TTM at 24, 72 (maximum levels for both TTG and TTM), and 120 hours. There was no statistically significant difference $(p>0.05)$ between the levels of TSP1 in TTG and TTM at baseline $(-1 \mathrm{~h}), 1$ week, and 2 weeks. (Figure 2(b)).

For both test groups, TTG and TTM, there were significant positive correlations between levels of PTX3 and TSP1 at 24 hours and poor correlations between levels of PTX 3 and TSP1 at 72 and 120 hours, 1 week, and 2 weeks (Tables 1 and 2). 
TABLE 1: Correlations between PTX3 and TSP1 levels at different time points in TTM. For the test group TTM there were significant positive correlations between levels of PTX3 and TSP1 at 24 hours $(r=0.972, p<0.05)$ and poor correlations between levels of PTX3 and TSP1 at 72 and 120 hours, 1 week, and 2 weeks (Pearson test for correlations).

\begin{tabular}{|c|c|c|c|c|c|c|}
\hline \multirow{2}{*}{ TSP1 levels in TTM } & \multicolumn{6}{|c|}{ PTX3 levels in TTM } \\
\hline & $-1 \mathrm{~h}$ & $24 \mathrm{~h}$ & $72 \mathrm{~h}$ & $120 \mathrm{~h}$ & $1 \mathrm{wk}$ & $2 \mathrm{wks}$ \\
\hline$-1 \mathrm{~h}$ & $r=0.113$ & - & - & - & - & - \\
\hline $24 \mathrm{~h}$ & - & $\mathbf{r}=\mathbf{0 . 9 7 2}$ & - & - & - & - \\
\hline $72 \mathrm{~h}$ & - & - & $r=0.474$ & - & - & - \\
\hline $120 \mathrm{~h}$ & - & - & - & $r=0.431$ & - & - \\
\hline $1 \mathrm{wk}$ & - & - & - & - & $r=0.37$ & - \\
\hline 2 wks & - & - & - & - & - & $r=0.331$ \\
\hline
\end{tabular}

TABLE 2: Correlations between PTX3 and TSP1 levels at different time points in TTG. For the test groups TTG there were significant positive correlations between levels of PTX3 and TSP1 at 24 hours $(r=0.984, p<0.05$ for TTG) and poor correlations between levels of PTX3 and TSP1 at 72 and 120 hours, 1 week, and 2 weeks (Pearson test for correlations).

\begin{tabular}{|c|c|c|c|c|c|c|}
\hline \multirow{2}{*}{ TSP1 levels in TTG } & \multicolumn{6}{|c|}{ PTX3 levels in TTG } \\
\hline & $-1 \mathrm{~h}$ & $24 \mathrm{~h}$ & $72 \mathrm{~h}$ & $120 \mathrm{~h}$ & $1 \mathrm{wk}$ & $2 \mathrm{wks}$ \\
\hline$-1 \mathrm{~h}$ & $r=0.032$ & - & - & - & - & - \\
\hline $24 \mathrm{~h}$ & - & $\mathrm{r}=\mathbf{0 . 9 8 4}$ & - & - & - & - \\
\hline $72 \mathrm{~h}$ & - & - & $r=0.42$ & - & - & - \\
\hline $120 \mathrm{~h}$ & - & - & - & $r=0.593$ & - & - \\
\hline $1 \mathrm{wk}$ & - & - & - & - & $r=0.564$ & - \\
\hline 2 wks & - & - & - & - & - & $r=0.002$ \\
\hline
\end{tabular}

\section{Discussion}

Wound healing is a complex biological process that consists of four phases: haemostasis, inflammation, proliferation, and remodelling of tissues [33]. Immediately after injury, the haemostasis begins, and proinflammatory cytokines and growth factors like TGF-beta, epithelial growth factor (EGF), VEGF, and fibroblasts growth factor (FGF) [34, 35] are released; thus the inflammatory stage is promoted. During this stage, macrophages and neutrophils infiltrate the wound bed and release other promoter cells of inflammation [36]. Angiogenesis is a part of the proliferation phase and is characterized by the formation of new blood vessels [37]. The final phase is the tissular remodelling; the vascular density in the wound returns to normal; this process could continue for years [35]. Angiogenesis and inflammation are two important processes for wound healing; investigation of their specific markers may offer information about its progression [19].

A recent narrative review on the fundamental clinical principles in periodontal plastic surgery and mucosal augmentation concludes that delicate tissue handling and tension-free wound closure represent prerequisites for optimal healing outcomes. Such procedures benefit nowadays from microsurgical techniques and magnification devices [38].

The clinical advantages of microsurgical instruments, techniques, and work under magnification in periodontology were first mentioned in the founding studies of Tibbetts and Shanelec [39] and Burkhardt and Hürzeler [40]. The same microsurgical approach was further designated as MIST (Minimally Invasive Surgical Technique) and used enamel matrix derivative as a regeneration agent in intrabony defects, with the observation of the same clinical excellent results [4143].

Wound healing characteristics in periodontal surgery for different surgical techniques were assessed especially by clinical parameters. Comparing the periodontal micro- and macrosurgery, clinical criteria were used, which indicated for microsurgery an increased comfort and gain in attachment in case of regenerative treatment of infraosseous lesions treatment $[15,44]$ or reduction of gingival recessions by plastic microsurgery [44-48]. Gingivectomy is the simplest technique of periodontal surgery, offering a good access and high predictability [9]; it is performed without vertical incisions or sutures, which are known to promote local inflammation $[10,11]$.

In the present study, the gingival enlargement as a result of orthodontic treatment, without attachment or bone loss, was excised by gingivectomy performed 1 month after cessation of orthodontic forces, to avoid the influence of the orthodontic tooth movements on the secretion of biomarkers in GCF, and 1 week after scaling, under continuous motivation for oral hygiene and a good control of plaque. Expression of certain biomarkers of inflammation and angiogenesis in GCF was used to assess the characteristics of the wound healing after using microsurgical instruments and the dental operating microscope in performing this simple technique.

The involvement of PTX3 in some general diseases characterized by an inflammatory status was proven in several studies. Elevated plasma levels of PTX3 were found in the dengue virus infection [20] and also in the severe meningococcal disease [49]. PTX3 association with sepsis was proven, 


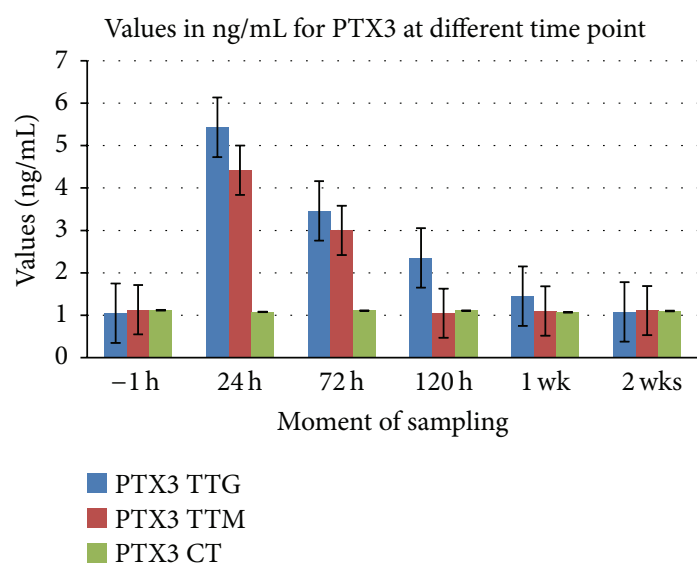

(a)

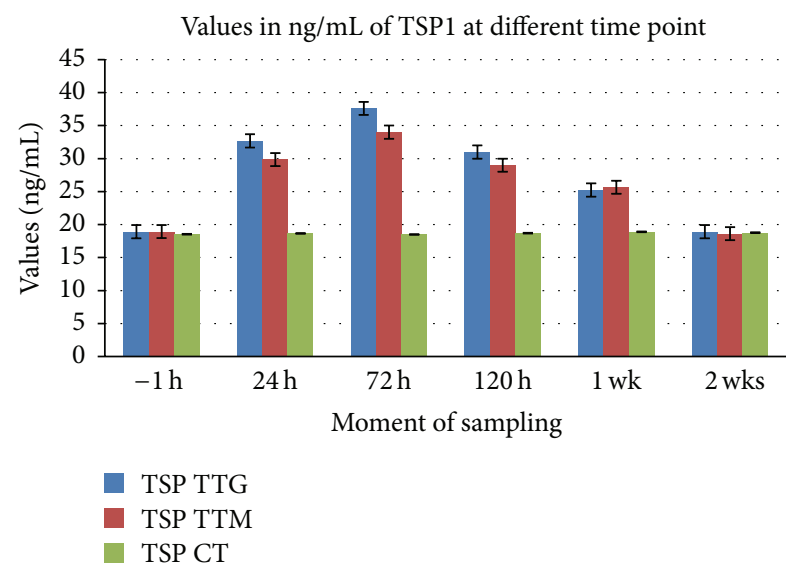

(b)

FIGURE 2: Differences between levels of PTX3 and TSP1 in TTG and TTM. (a) Statistically significant differences between PTX3 at 24, 72, and $120 \mathrm{~h}$ and baseline in TTG and statistically significant differences between PTX3 at 24 and $72 \mathrm{~h}$ and baseline in TTM; (b) statistically significant differences between TSP1 at 24, 72, and $120 \mathrm{~h}$ and $1 \mathrm{wk}$ and baseline in TTG and statistically significant differences between TSP1 at 24,72 , and $120 \mathrm{~h}$ and $1 \mathrm{wk}$ and baseline in TTM.

and the effect of antioxidant treatment on PTX3 levels was demonstrated [21]. The implication of PTX3 in the innate immunity [50] was studied, and levels of PTX3 are considered a marker of inflammation in psoriasis, as well [51]. The involvement of PTX3 in angiogenesis was also demonstrated. A FGF2-binding domain in the $\mathrm{N}$-terminal extension of PTX3 spanning the PTX3-[97-110] region was identified, pointing to a novel function for the $\mathrm{N}$-terminal extension of PTX3 and underlining the complexity of the PTX3 molecule for modular humoral pattern recognition [27]. This suggests that PTX3 may exert a modulatory function by limiting the angiogenic activity of FGF2 [52], FGF2 being found in human and porcine wound fluid, particularly at early stages after injuries [34, 53-55].

Thrombospondin 1 (TSP1) is a glycoprotein and is one of the endogenous inhibitors of angiogenesis with multiple active domains [29]. The ability of TSP1 to inhibit vascular growth appears to be located within the last 2 type 1 repeats. Therefore, inhibition of binding or further sequestration of FGF2 is the most likely mechanism of action of this aminoterminal portion of the type 1 repeats $[28,56]$. These findings may support the idea that between the levels of PTX3 and TSP1 may be a correlation, both biomarkers being involved in limiting the angiogenic action of FGF2.

In the present study, there were no significant differences between the levels of PTX3 and TSP1 levels for CT and TTM or TTG before surgery ( $-1 \mathrm{~h}$ as baseline). Even if, for TTM and TTG, HTG was present, scaling was performed 1 week before surgery, and oral hygiene was good, the HTG did not display any clinical signs of inflammation, explaining the lack of significant differences between CT, TTM, and TTG. PTX3 levels increase in the first 24 hours, starting to decrease afterwards for both types of surgery, but the levels are lower in case of microsurgery compared to gingivectomy without magnification, indicating a lesser intense inflammatory reaction.
Reduction of PTX3 levels after $24 \mathrm{~h}$ is faster and more abrupt in case of microsurgery, reaching levels before intervention at $120 \mathrm{~h}$, while, for gingivectomy without magnification, levels before surgery are reached at 1 week. These findings could suggest that inflammation of shorter intensity and duration in case of microsurgery may explain the higher comfort of the patient reported by some authors [13]. Reduced inflammatory reaction could be explained by less mechanical trauma given by the use of a microsurgical approach, including microsurgical instruments, and so an improvement of wound healing is obtained [38].

TSP1 reaches maximal values at 72 hours from intervention in both situations after a continuous increase, but as for PTX3, levels in case of microsurgery are lower than that of gingivectomy without magnification. In case of microsurgery, TSP1 level reaches the value before intervention faster than in case of gingivectomy without magnification, which may suggest that angiogenesis is faster in this case and so is the wound healing.

The results of this study show a stronger correlation between the PTX3 and TSP1 levels at $24 \mathrm{~h}$ from surgical intervention for both types of surgery, possibly related to the expression of FGF2, which is reported to be maximal in the first hours from injury [31]. Future studies determining proand antiangiogenic markers, including different FGFs, could bring new insights to this possible correlation.

Further studies assessing the expression of different biomarkers possibly involved in wound healing after more sophisticated usual surgical techniques could correlate the results of the present study to other factors and find the place occupied by these substances in the mediators' fall that is activated during this complex process.

\section{Conclusions}

Within the limitations of this study, the results seem to sustain the involvement of PTX3 and TSP1 in the processes of 
inflammation and angiogenesis in wound healing in patients with postorthodontic gingivectomy, showing a change in time of PTX3 and TSP1 levels in GCF of these patients, regardless of the use of microsurgical instruments and magnification of a dental microscope. The dynamics of PTX3 and TSP1 levels suggest a reduced inflammation and a faster angiogenesis using microsurgery, which could explain the more favorable clinical course of wound healing reported by other previous studies.

\section{Competing Interests}

The authors declare that there is no conflict of interests regarding the publication of this paper.

\section{Authors' Contributions}

All authors had equal contribution as the first author and can be all regarded, therefore, as main authors.

\section{References}

[1] I. B. Lamster, R. L. Oshrain, L. A. Fiorello, R. S. Celenti, and J. M. Gordon, "A comparison of 4 methods of data presentation for lysosomal enzyme activity in gingival crevicular fluid," Journal of Clinical Periodontology, vol. 15, no. 6, pp. 347-352, 1988.

[2] P. M. Duarte, M. da Rocha, E. Sampaio et al., "Serum levels of cytokines in subjects with generalized chronic and aggressive periodontitis before and after non-surgical periodontal therapy: a pilot study," Journal of Periodontology, vol. 81, no. 7, pp. 10561063, 2010.

[3] G. Emingil, H. Kuula, T. Sorsa, and G. Atilla, "Gingival crevicular fluid matrix metalloproteinase-25 and -26 levels in periodontal disease," Journal of Periodontology, vol. 77, no. 4, pp. 664-671, 2006.

[4] A. M. Marcaccini, C. A. Meschiari, L. R. Zuardi et al., "Gingival crevicular fluid levels of MMP-8, MMP-9, TIMP-2, and MPO decrease after periodontal therapy," Journal of Clinical Periodontology, vol. 37, no. 2, pp. 180-190, 2010.

[5] T. Ingman, S. Apajalahti, P. Mäntylä, P. Savolainen, and T. Sorsa, "Matrix metalloproteinase-1 and -8 in gingival crevicular fluid during orthodontic tooth movement: a pilot study during 1 month of follow-up after fixed appliance activation," European Journal of Orthodontics, vol. 27, no. 2, pp. 202-207, 2005.

[6] Y. Ren, H. Hazemeijer, B. de Haan, N. Qu, and P. de Vos, "Cytokine profiles in crevicular fluid during orthodontic tooth movement of short and long durations," Journal of Periodontology, vol. 78, no. 3, pp. 453-458, 2007.

[7] M. M. Bildt, M. Bloemen, A. M. Kuijpers-Jagtman, and J. W. Von den Hoff, "Matrix metalloproteinases and tissue inhibitors of metalloproteinases in gingival crevicular fluid during orthodontic tooth movement," European Journal of Orthodontics, vol. 31, no. 5, pp. 529-535, 2009.

[8] B. M. Eley and S. W. Cox, "Cathepsin B/L-, elastase-, tryptase-, trypsin- and dipeptidyl peptidase IV-like activities in gingival crevicular fluid: a comparison of levels before and after periodontal surgery in chronic periodontitis patients," Journal of Periodontology, vol. 63, no. 5, pp. 412-417, 1992.

[9] E. S. Cohen, Atlas of Cosmetic and Reconstructive Periodontal Surgery, PMPH-USA, 2007.
[10] S. Dibart and T. Dietrich, Practical Periodontal Diagnosis and Treatment Planning, Willey-Blackwell, 2013.

[11] E. J. C. van Rijssel, R. Brand, C. Admiraal, I. Smit, and J. B. Trimbos, "Tissue reaction and surgical knots: the effect of suture size, knot configuration, and knot volume," Obstetrics and Gynecology, vol. 74, no. 1, pp. 64-68, 1989.

[12] K. A. Selvig, G. R. Biagiotti, K. N. Leknes, and U. M. E. Wikesjö, "Oral tissue reactions to suture materials," International Journal of Periodontics and Restorative Dentistry, vol. 18, no. 5, pp. 475487, 1998.

[13] E. S. Cohen, "Microsurgery," in Atlas of Cosmetic and Reconstructive Periodontal Surgery, pp. 435-436, PMPH-USA, 2007.

[14] S. Bittencourt, É. Del Peloso Ribeiro, E. A. Sallum, F. H. Nociti Jr., and M. Z. Casati, "Surgical microscope may enhance root coverage with subepithelial connective tissue graft: a randomized-controlled clinical trial," Journal of Periodontology, vol. 83, no. 6, pp. 721-730, 2012.

[15] H. Wachtel, G. Schenk, S. Böhm, D. Weng, O. Zuhr, and M. B. Hürzeler, "Microsurgical access flap and enamel matrix derivative for the treatment of periodontal intrabony defects: a controlled clinical study," Journal of Clinical Periodontology, vol. 30, no. 6, pp. 496-504, 2003.

[16] J. A. Nunley, The Achilles Tendon: Treatment and Rehabilitation, Springer, New York, NY, USA, 2008.

[17] M. S. Agren, "Gelatinase activity during wound healing," British Journal of Dermatology, vol. 131, no. 5, pp. 634-640, 1994.

[18] T. Salo, M. Makela, M. Kylmaniemi, H. Autio-Harmainen, and H. Larjava, "Expression of matrix metalloproteinase-2 and -9 during early human wound healing," Laboratory Investigation, vol. 70, no. 2, pp. 176-182, 1994.

[19] J. P. Polverini, "Angiogenesis and wound healing: basic discoveries, clinical implications and therapeutic opportunities," in Oral Wound Healing: Cell Biology and Clinical Management, $\mathrm{H}$. Larjava, Ed., pp. 175-195, John Wiley \& Sons, New York, NY, USA, 1st edition, 2012.

[20] A. T. A. Mairuhu, G. Peri, T. E. Setiati et al., "Elevated plasma levels of the long pentraxin, pentraxin 3, in severe dengue virus infections," Journal of Medical Virology, vol. 76, no. 4, pp. 547552, 2005.

[21] A. L. Hill, D. A. Lowes, N. R. Webster, C. C. Sheth, N. A. R. Gow, and H. F. Galley, "Regulation of pentraxin-3 by antioxidants," British Journal of Anaesthesia, vol. 103, no. 6, pp. 833-839, 2009.

[22] A. R. Goodman, D. E. Levy, L. F. L. Reis, and J. Vilcek, "Differential regulation of TSG-14 expression in murine fibroblasts and peritoneal macrophages," Journal of Leukocyte Biology, vol. 67, no. 3, pp. 387-395, 2000.

[23] S. Jaillon, G. Peri, Y. Delneste et al., "The humoral pattern recognition receptor PTX3 is stored in neutrophil granules and localizes in extracellular traps," Journal of Experimental Medicine, vol. 204, no. 4, pp. 793-804, 2007.

[24] A. R. Pradeep, R. Kathariya, N. M. Raghavendra, and A. Sharma, "Levels of pentraxin-3 in gingival crevicular fluid and plasma in periodontal health and disease," Journal of Periodontology, vol. 82, no. 5, pp. 734-741, 2011.

[25] P. Surlin, A. M. Rauten, I. Silosi, and L. Foia, "Pentraxin-3 levels in gingival crevicular fluid during orthodontic tooth movement in young and adult patients," Angle Orthodontist, vol. 82, no. 5, pp. 833-838, 2012.

[26] M. Rusnati, M. Camozzi, E. Moroni et al., "Selective recognition of fibroblast growth factor-2 by the long pentraxin PTX3 inhibits angiogenesis," Blood, vol. 104, no. 1, pp. 92-99, 2004. 
[27] M. Camozzi, M. Rusnati, A. Bugatti et al., "Identification of an antiangiogenic FGF2-binding site in the $\mathrm{N}$ terminus of the soluble pattern recognition receptor PTX3," The Journal of Biological Chemistry, vol. 281, no. 32, pp. 22605-22613, 2006.

[28] M. L. Iruela-Arispe, A. Luque, and N. Lee, "Thrombospondin modules and angiogenesis," International Journal of Biochemistry and Cell Biology, vol. 36, no. 6, pp. 1070-1078, 2004.

[29] M. Rusnati, C. Urbinati, S. Bonifacio, M. Presta, and G. Taraboletti, "Thrombospondin-1 as a paradigm for the development of antiangiogenic agents endowed with multiple mechanisms of action," Pharmaceuticals, vol. 3, no. 4, pp. 1241-1278, 2010.

[30] A. Bökenkamp, B. Bohnhorst, C. Beier, N. Albers, G. Offner, and J. Brodehl, "Nifedipine aggravates cyclosporine A-induced gingival hyperplasia," Pediatric Nephrology, vol. 8, no. 2, pp. 181185, 1994.

[31] S. Uematsu, M. Mogi, and T. Deguchi, "Interleukin (IL)-1 $\beta$, IL6 , tumor necrosis factor- $\alpha$, epidermal growth factor, and $\beta 2$ microglobulin levels are elevated in gingival crevicular fluid during human orthodontic tooth movement," Journal of Dental Research, vol. 75, no. 1, pp. 562-567, 1996.

[32] X. Zhang, H. Meng, L. Xu et al., "Vitamin D-binding protein levels in plasma and gingival crevicular fluid of patients with generalized aggressive periodontitis," International Journal of Endocrinology, vol. 2014, Article ID 783575, 6 pages, 2014.

[33] A. Gosain and L. A. DiPietro, "Aging and wound healing," World Journal of Surgery, vol. 28, no. 3, pp. 321-326, 2004.

[34] S. Werner and R. Grose, "Regulation of wound healing by growth factors and cytokines," Physiological Reviews, vol. 83, no. 3, pp. 835-870, 2003.

[35] S. Guo and L. A. DiPietro, "Factors affecting wound healing," Journal of Dental Research, vol. 89, no. 3, pp. 219-229, 2010.

[36] A. C. L. Campos, A. K. Groth, and A. B. Branco, "Assessment and nutritional aspects of wound healing," Current Opinion in Clinical Nutrition and Metabolic Care, vol. 11, no. 3, pp. 281-288, 2008.

[37] H. F. Dvorak, "Tumors: wounds that do not heal: similarities between tumor stroma generation and wound healing," The New England Journal of Medicine, vol. 315, no. 26, pp. 1650-1659, 1986.

[38] R. Burkhardt and N. P. Lang, "Fundamental principles in periodontal plastic surgery and mucosal augmentation-a narrative review," Journal of Clinical Periodontology, vol. 41, pp. S98-S107, 2014.

[39] L. S. Tibbetts and D. Shanelec, "Periodontal microsurgery," Dental Clinics of North America, vol. 42, no. 2, pp. 339-359, 1998.

[40] R. Burkhardt and M. B. Hürzeler, "Utilization of the surgical microscope for advanced plastic periodontal surgery," Practical Periodontics and Aesthetic Dentistry, vol. 12, no. 2, pp. 171-180, 2000.

[41] P. Cortellini and M. S. Tonetti, "A minimally invasive surgical technique with an enamel matrix derivative in the regenerative treatment of intra-bony defects: a novel approach to limit morbidity," Journal of Clinical Periodontology, vol. 34, no. 1, pp. 87-93, 2007.

[42] P. Cortellini and M. S. Tonetti, "Minimally invasive surgical technique and enamel matrix derivative in intra-bony defects. I: clinical outcomes and morbidity," Journal of Clinical Periodontology, vol. 34, no. 12, pp. 1082-1088, 2007.

[43] P. Cortellini, G. Pini-Prato, M. Nieri, and M. S. Tonetti, "Minimally invasive surgical technique and enamel matrix derivative in intrabony defects: 2. Factors associated with healing outcomes," The International Journal of Periodontics \& Restorative Dentistry, vol. 29, no. 3, pp. 257-265, 2009.

[44] O. Zuhr, S. Fickl, H. Wachtel, W. Bolz, and M. B. Hürzeler, "Covering of gingival recessions with a modified microsurgical tunnel technique: case report," International Journal of Periodontics and Restorative Dentistry, vol. 27, no. 5, pp. 457-463, 2007.

[45] L. Francetti, M. Del Fabbro, S. Calace, T. Testori, and R. L. Weinstein, "Microsurgical treatment of gingival recession: a controlled clinical study," International Journal of Periodontics and Restorative Dentistry, vol. 25, no. 2, pp. 181-188, 2005.

[46] R. Burkhardt and N. P. Lang, "Coverage of localized gingival recessions: comparison of micro- and macrosurgical techniques," Journal of Clinical Periodontology, vol. 32, no. 3, pp. 287293, 2005.

[47] S. Fickl, T. Thalmair, M. Kebschull, S. Böhm, and H. Wachtel, "Microsurgical access flap in conjunction with enamel matrix derivative for the treatment of intra-bony defects: a controlled clinical trial," Journal of Clinical Periodontology, vol. 36, no. 9, pp. 784-790, 2009.

[48] P. F. Andrade, M. F. M. Grisi, A. M. Marcaccini et al., "Comparison between micro-and macrosurgical techniques for the treatment of localized gingival recessions using coronally positioned flaps and enamel matrix derivative," Journal of Periodontology, vol. 81, no. 11, pp. 1572-1579, 2010.

[49] T. Sprong, G. Peri, C. Neeleman et al., "Pentraxin 3 and Creactive protein in severe meningococcal disease," Shock, vol. 31, no. 1, pp. 28-32, 2009.

[50] A. Mantovani, C. Garlanda, A. Doni, and B. Bottazzi, "Pentraxins in innate immunity: from C-reactive protein to the long pentraxin PTX3," Journal of Clinical Immunology, vol. 28, no. 1, pp. 1-13, 2008.

[51] V. Bevelacqua, M. Libra, M. C. Mazzarino et al., "Long pentraxin 3: a marker of inflammation in untreated psoriatic patients," International Journal of Molecular Medicine, vol. 18, no. 3, pp. 415-423, 2006.

[52] D. Leali, P. Alessi, D. Coltrini, M. Rusnati, L. Zetta, and M. Presta, "Fibroblast growth factor-2 antagonist and antiangiogenic activity of long-pentraxin 3-derived synthetic peptides," Current Pharmaceutical Design, vol. 15, no. 30, pp. 3577-3589, 2009.

[53] K. Breuing, C. Andree, G. Helo, J. Slama, P. Y. Liu, and E. Eriksson, "Growth factors in the repair of partial thickness porcine skin wounds," Plastic and Reconstructive Surgery, vol. 100, no. 3, pp. 657-664, 1997.

[54] W. Y. J. Chen, A. A. Rogers, and M. J. Lydon, "Characterization of biologic properties of wound fluid collected during early stages of wound healing," Journal of Investigative Dermatology, vol. 99, no. 5, pp. 559-564, 1992.

[55] M. G. Tonnesen, X. Feng, and R. A. F. Clark, "Angiogenesis in wound healing," Journal of Investigative Dermatology Symposium Proceedings, vol. 5, no. 1, pp. 40-46, 2000.

[56] B. Margosio, D. Marchetti, V. Vergani et al., "Thrombospondin 1 as a scavenger for matrix-associated fibroblast growth factor 2," Blood, vol. 102, no. 13, pp. 4399-4406, 2003. 


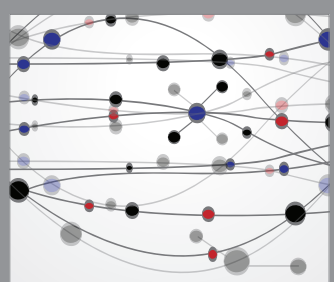

The Scientific World Journal
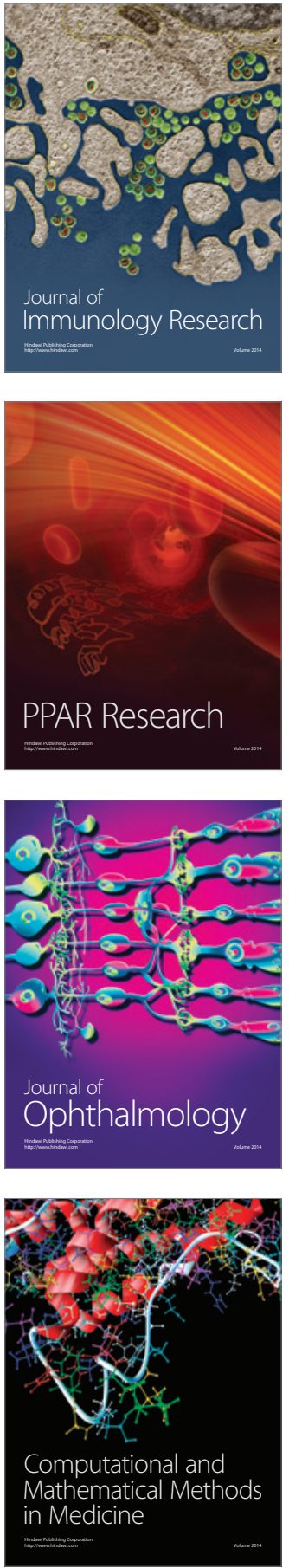

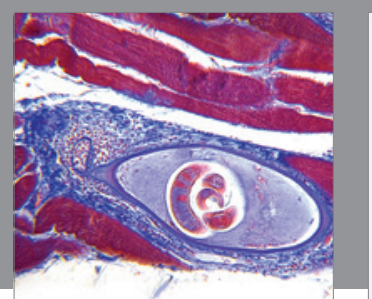

Gastroenterology Research and Practice

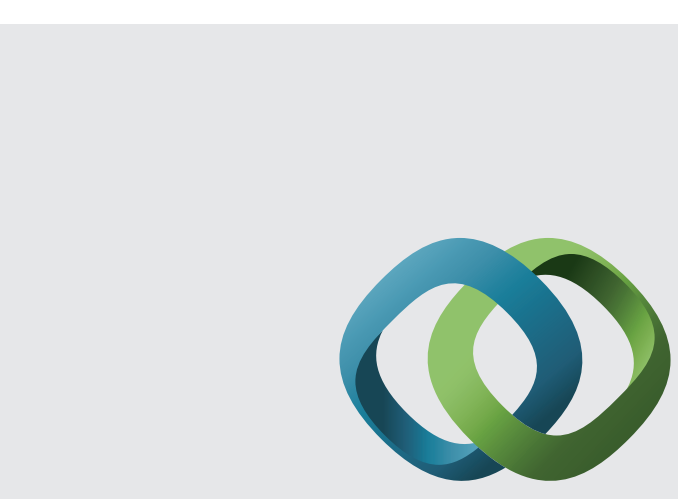

\section{Hindawi}

Submit your manuscripts at

http://www.hindawi.com
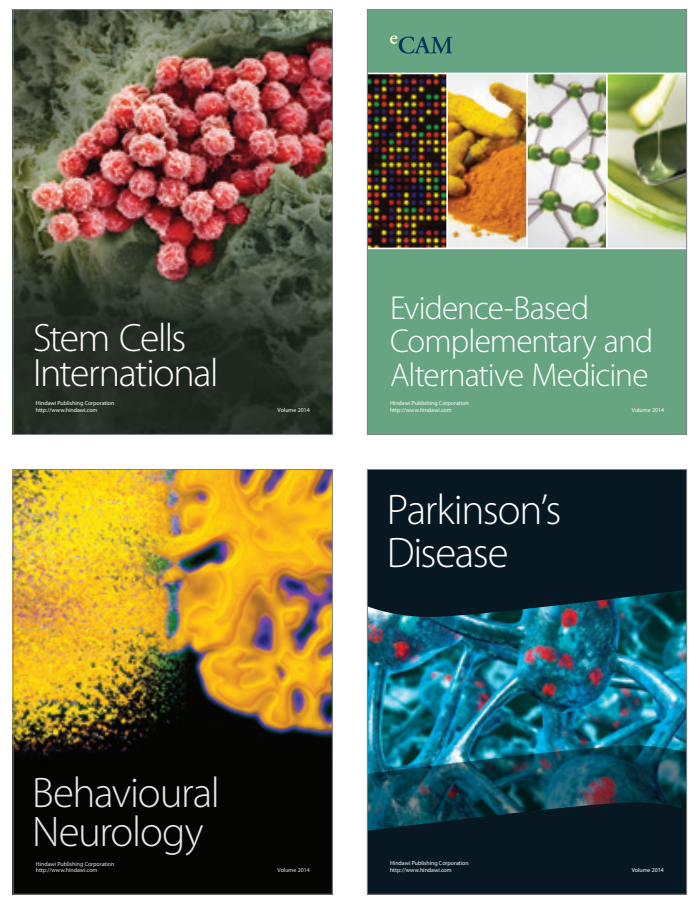
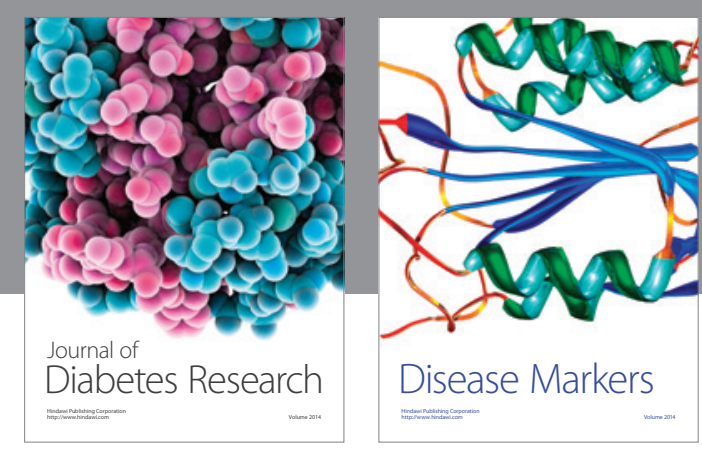

Disease Markers
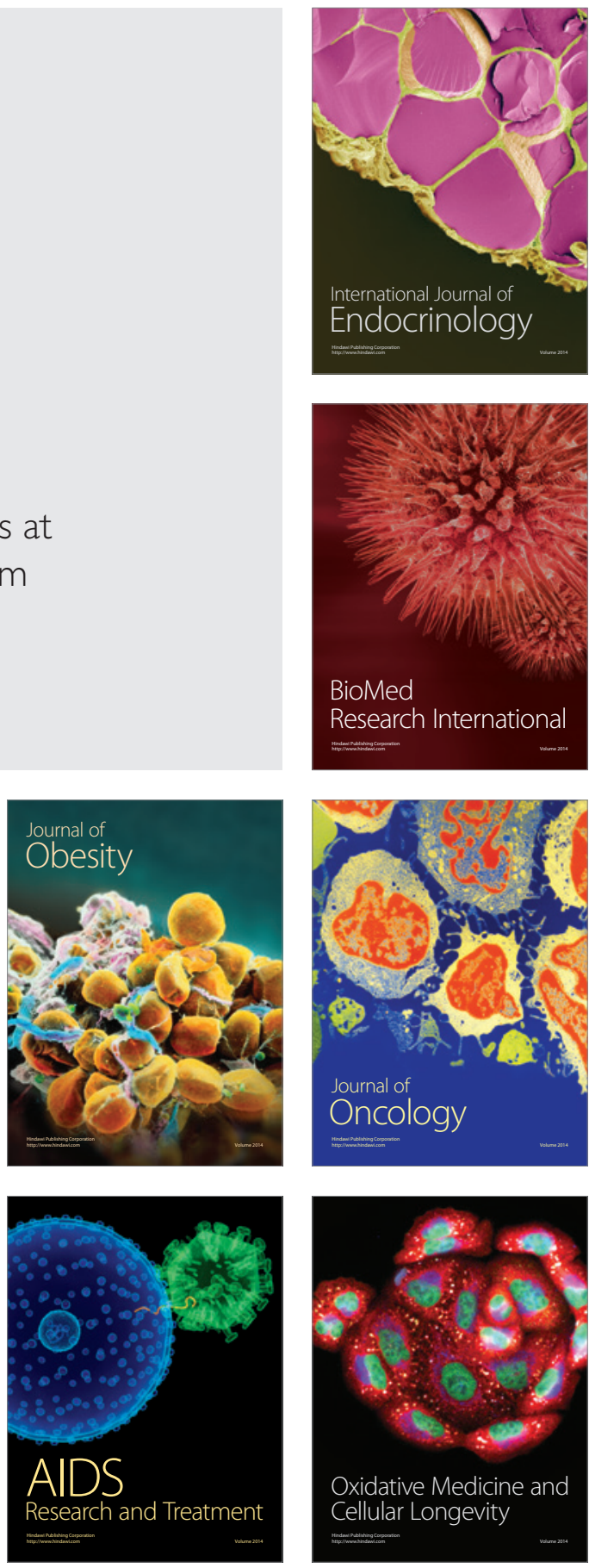